\title{
Training with anxiety: short- and long-term effects on police officers' shooting behavior under pressure
}

\author{
Arne Nieuwenhuys $\cdot$ Raôul R. D. Oudejans
}

Received: 29 June 2010/ Accepted: 7 March 2011/Published online: 24 March 2011

(C) The Author(s) 2011. This article is published with open access at Springerlink.com

\begin{abstract}
We investigated short- and long-term effects of training with anxiety on police officers' shooting behavior under pressure. Using a pretest, posttest, and retention test design, 27 police officers executed a shooting exercise against an opponent that did (high anxiety) or did not (low anxiety) shoot back using colored soap cartridges. During the training sessions, the experimental group practiced with anxiety and the control group practiced without anxiety. At the pretest, anxiety had a negative effect on shot accuracy for both groups. At the posttest, shot accuracy of the experimental group no longer deteriorated under anxiety, while shot accuracy of the control group was still equally affected. At the retention test, 4 months after training, positive results for the experimental group remained present, indicating that training with anxiety may have positive short- and long-term effects on police officers' shot accuracy under pressure. Additional analyses showed that these effects are potentially related to changes in visual attention on task-relevant information.
\end{abstract}

Keywords Attentional control theory - Anxiety · Choking under pressure Perceptual-motor performance . Police

Specific parts of this study focusing on practical implications of the findings and without full description of statistics have been published in Dutch in a research report for the Dutch police.

A. Nieuwenhuys $(\bowtie) \cdot$ R. R. D. Oudejans

Research Institute MOVE, Faculty of Human Movement

Sciences, VU University Amsterdam, Van der Boechorstraat 9,

1081 BT Amsterdam, The Netherlands

e-mail: a.nieuwenhuys@vu.nl

\section{Introduction}

Police work is often accompanied by high levels of acute stress (e.g., Anderson et al. 2002), for instance, when chasing suspects or-in more severe cases-using a firearm. Nevertheless, regular police training focuses predominantly on the technical, tactical, and physical aspects of performance and largely neglects the role of psychological factors such as stress and anxiety (Oudejans 2008; see also Nieuwenhuys et al. 2009; Nieuwenhuys and Oudejans 2010). As such, one may wonder whether "ordinary" police officers are properly prepared to perform well under stressful circumstances (Murray 2004).

Annual reports of police performance in the United States show that while police officers perform relatively well on low-pressure shooting tests (with hit percentages above 90\%), they perform substantially worse when firing in the line of duty (with hit percentages around or below 50\%; e.g., Morrison and Vila 1998). This was also shown by Oudejans (2008) and Nieuwenhuys and Oudejans (2010), who found that police officers' shooting accuracy decreased significantly when they performed in highanxiety conditions in which opponents shot back using colored soap cartridges. Given the criticality of successful police performance, these results specify a need to further our understanding of the anxiety-performance relationship and to find ways to improve police officers' shooting performance under stressful circumstances (cf. Nieuwenhuys and Oudejans 2010).

According to attentional control theory (Eysenck et al. 2007), anxiety affects performance because top-down (goal-directed) attentional control is reduced as a result of increased bottom-up (stimulus-driven) processes. More attention is spent on worries and detecting the sources of threat (stimulus driven), while less attention is spent on the 
task (goal directed; see Deffenbacher et al. 2004, for a discussion of comparable processes involving "arousal" and "activation" modes of attentional control). In addition to these negative effects of anxiety, Eysenck et al. (2007) hypothesized that anxiety may also serve a motivational function, as individuals may try to compensate for the debilitative effects of anxiety by increasing the amount of mental effort they invest in attempting to maintain a taskrelevant focus. As such, anxiety may affect processing efficiency (because more effort is needed to obtain the same result), while performance effectiveness remains the same.

Although attentional control theory was originally developed to explain the effects of anxiety on cognitive performance, an increasing number of studies has provided support for its predictions within a perceptual-motor context (e.g., Coombes et al. 2009; Nieuwenhuys and Oudejans 2010; Nieuwenhuys et al. 2008; Oudejans and Pijpers 2009, 2010; Wilson et al. 2009). For example, Nieuwenhuys and Oudejans (2010) showed that under anxiety police officers increase the speed with which they perform, leaving less time to shoot accurately at the targets. In addition, the officers no longer looked straight at the opponent and blinked more often, which led to increases in the time they had their eyes closed. These results occurred despite of extra mental effort that was invested. In line with attentional control theory, this indicated that police officers' behavior became less efficient and more stimulus driven under anxiety, leading to a strong decrease in overall task performance.

Recently, Oudejans (2008) and Oudejans and Pijpers $(2009,2010)$ showed that training with anxiety may lead to improved performance under stressful circumstances (cf. Beilock and Carr 2001; Driskell et al. 2001). In the study of Oudejans (2008), one group of police officers (the experimental group) practiced handgun shooting with high levels of anxiety as the opponent shot back using colored soap cartridges. The control group practiced with low anxiety on cardboard targets. Both groups received three training sessions of $1 \mathrm{~h}$. While at the outset, both groups performed worse in front of an opponent firing back, after the training sessions shot accuracy of the experimental group no longer deteriorated while that of the control group was still negatively affected. These results are similar to those obtained with expert and novice athletes (Oudejans and Pijpers 2009, 2010).

Explaining these effects, Oudejans and Nieuwenhuys (2009) hypothesized that individuals that have trained with anxiety may invest extra mental effort more efficiently and effectively, while individuals that have not trained with anxiety will also invest extra effort but do so ineffectively, as it is not directed at the right processes. For example, in the experiments of Oudejans and Pijpers $(2009,2010)$ both the experimental and the control groups showed consistent increases in mental effort when performing under anxiety. However, only after training with anxiety did the performance of the experimental groups improve, providing an indirect indication that in some way their additional effort became increasingly effective (Oudejans and Pijpers 2009, 2010).

Despite these encouraging results, much is still unknown about the processes that are involved in training with anxiety (cf. Nieuwenhuys and Oudejans 2010). Furthermore, it is unclear whether the positive results of training with anxiety (Oudejans 2008; Oudejans and Pijpers 2009, 2010) remain over a longer period of time (e.g., several months). Therefore, in the present study, we investigated short- as well as long-term effects of training with anxiety on police officers' handgun shooting behavior under pressure. We tested police officers' shooting behavior at three instances, namely just before, just after, and 4 months after a series of four training sessions in which police officers practiced their handgun shooting under high-anxiety conditions (experimental group) or low-anxiety conditions (control group). In all cases, anxiety was manipulated by having participants perform against opponents that did or did not shoot back with colored soap cartridges (cf. Nieuwenhuys and Oudejans 2010; Oudejans 2008).

We measured participants' performance effectiveness (shot accuracy) and assessed several behavioral processes (movement speed, visual orientation, blink behavior, and gaze behavior) that provided possible indications of (regained) efficiency (cf. Nieuwenhuys and Oudejans 2010). In addition, we measured the perceived amount of mental effort invested in task execution. Following attentional control theory (Eysenck et al. 2007), we expected that anxiety would initially reduce efficiency (i.e., how performance is achieved) and cause a decrease in participants' shot accuracy (Oudejans 2008). That is, participants were expected to speedup their performance, change their visual orientation, and increase their blinking when performing under anxiety (Nieuwenhuys and Oudejans 2010). Furthermore, participants were expected to show reduced attentional control, meaning that they would spend less time looking at the targets (reduced goal-directed attention) and more time looking at the head or gun of the opponent (increased stimulus-driven attention; Nieuwenhuys and Oudejans 2010; Vickers and Williams 2007; Wilson et al. 2009). Moreover, we expected the duration of participants' final fixations on the targets to become shorter under high anxiety. In the perceptual-motor literature, it is well established that in far aiming tasks (such as handgun shooting), longer final fixations are associated with better performance, as more time is provided to accurately adjust movements on the basis of visual information (e.g., Vickers 2007). Regarding pressure situations, anxiety-induced decreases in performance have been related to decreases in 
the duration of the final fixation on the target (e.g., Vickers and Williams 2007; Wilson et al. 2009). In line with attentional control theory, it has been suggested that such a reduction in the duration of the final fixation on the target, may be indicative of a loss of (goal-directed) attentional control (Wilson et al. 2009; cf. Eysenck et al. 2007).

With regard to the current experiment, we expected that after the training sessions, shot accuracy of the experimental group would no longer deteriorate under anxiety, while that of the control group would still be equally harmed (Oudejans 2008; Oudejans and Pijpers 2009, 2010). Improved accuracy of the experimental group was expected to be accompanied by improved efficiency, meaning that participants would no longer speedup their performance, no longer change their visual orientation, and no longer increase their blinking. In addition, the experimental group was expected to show improved attentional control under anxiety, as would be indicated by maintaining relatively long final fixations on the target areas and reduced (visual) distraction from other sources (e.g., Wilson et al. 2009). Finally, the effects of training with anxiety are believed to be learning effects (rather than incidental performance effects), in the sense that individuals actually learn to execute the practiced task with processes accompanying anxiety (Oudejans and Nieuwenhuys 2009). As such, we expected that the positive results of training with anxiety would be robust and would still be present at a retention test, 4 months after the training sessions (cf. Romano et al. 2010; Sauer et al. 2000).

\section{Method}

The experiment was approved by the ethics committee of the research institute. Given the involvement of firearms, it was executed under the responsibility of certified police firearms instructors, following their standard safety protocol.

\section{Participants}

Twenty-seven police officers, who volunteered to participate, were randomly divided into two groups (i.e., experimental and control). The experimental group consisted of 13 police officers (12 men, 1 woman) with a mean age of 34.62 years $(\mathrm{SD}=7.42)$ and a mean working experience of 11.62 years $(\mathrm{SD}=7.08)$. The control group consisted of 14 police officers (13 men, 1 woman) with a mean age of 34.79 years $(\mathrm{SD}=6.49)$ and a mean working experience of 11.5 years $(\mathrm{SD}=5.71)$. There were no significant differences between the age and the working experience of both groups ( $t \mathrm{~s}<1, P \mathrm{~s}>0.90$ ).
All participants had a full license to carry their handgun on duty. Among them, 19 reported to have been confronted at least once with an armed and dangerous criminal, 15 reported to have drawn their own handgun on such an occasion, and 3 had actually encountered situations in which they had to fire at a suspect. None of the participants had ever been shot at. With regard to the frequency of occurrence of these experiences, no significant difference was found between the two groups, $\chi^{2}(1)=2.6, P=0.86$.

Finally, participants' trait anxiety scores were significantly lower than the norm (i.e., 36.1; with $M=26.46$, $\mathrm{SD}=4.35, t(12)=8.483, P<0.001$, for the experimental group; and $M=28.93, \quad \mathrm{SD}=7.52, \quad t(13)=3.867$, $P=0.002$, for the control group; STAI A-Trait Scale; Van der Ploeg et al. 1980). These results show that participants had no extraordinary tendency to respond to specific situations with elevations in state anxiety. Therefore, any increases that would be found in participants' state anxiety during the experiment could be safely attributed to a successful pressure manipulation. Before the experiment started, all participants provided written informed consent.

\section{Design, experimental task, and conditions}

The experiment consisted of three tests and four training sessions. After a pretest, there were four training sessions in 4 weeks ( 1 per week), followed by a posttest, within 2 weeks after the last training session. A retention test was performed 4 months after the last training session. Between groups (experimental and control), there were no differences in the time lag between training sessions and tests. ${ }^{1}$

\section{Test sessions}

Each test consisted of a low-anxiety and high-anxiety condition, counterbalanced among participants. In both conditions, participants performed a shooting exercise which consisted of 10 repetitive trials in which they had to fire 4 rounds (totaling 40 rounds per condition) at an opponent fitted with white target areas (one on the chest: $28 \mathrm{~cm} \times$ $28 \mathrm{~cm}$, and two on the upper legs: $12 \mathrm{~cm} \times 35 \mathrm{~cm}$; cf. Nieuwenhuys and Oudejans 2010). The distance between the participant and the opponent was $5 \mathrm{~m}$, which is in line with average shooting distances seen in reality (e.g., Naeyé et al. 2001).

Beginning at a starting signal, participants fired one round at the opponent's right leg target, made a step to the right, fired one round at the opponent's left leg target, reloaded their handgun, fired one round at the opponent's

\footnotetext{
${ }^{1}$ Due to personal circumstances two participants (one from each group) could not be present at the retention test.
} 
chest target, stepped back to the left, and fired a final round at the chest target.

In the low-anxiety (LA) condition, the opponent was a life-size mannequin that stood straight-up facing the participants, wearing a black protective overall, facemask, throat protector, and hand gloves. In the high-anxiety (HA) condition, the opponent was an experienced police firearms instructor, also standing still in the same position, wearing the same clothes and protective items, and fitted with the same targets. Regardless of the participants' performance, the instructor occasionally fired back using colored soap cartridges. Being hit with these cartridges produced a sensation of pain, the threat of which was known to cause an increase in the participants' state anxiety (Nieuwenhuys and Oudejans 2010; Oudejans 2008). The opponent shot back on a limited number of trials (i.e., 7 shots in total, not all hits, and randomly divided over trials).

\section{Training sessions}

In between the pre- and posttest, participants of both groups received four training sessions of $1 \mathrm{~h}$. During these training sessions, participants executed several shooting exercises that were comparable to the test exercise, but took place in a more realistic environment at the police academy's training facilities (e.g., a police car, a building, and a shopping street). ${ }^{2}$ The total number of rounds that participants' fired during each of these training sessions was 12 (totaling 48 for all the training sessions together). The training exercises were the same for both groups, with the sole difference that the experimental group practiced under additional pressure against an opponent that occasionally fired back. The control group practiced without additional pressure and shot at the mannequin or cardboard targets.

\section{Experimental setup}

Test and training sessions were set up at the training facilities of the police academy. Participants shot with 9-mm handguns, identical to their duty weapon (Walther P5), and specifically prepared to fit colored soap cartridges (Simunition $^{\circledR}$, FX Marking Ammunition).

\section{Test sessions}

The tests were performed in a large room. Participants were recorded on video from the side using a digital video camera (Canon ZR 850; $29.97 \mathrm{~Hz}$ ). Furthermore, shooting times were registered with a shot timer. Finally, participants wore a mobile eye tracker (Applied Science

\footnotetext{
${ }^{2}$ Details about the training exercises can be obtained from the authors upon request.
}

Laboratories, Bedford, USA). The "mobile eye" is a monocular system that consists of two cameras, an eye camera, and a scene camera $(29.97 \mathrm{~Hz})$, which are mounted on a pair of glasses. The system combines the images of both cameras to assess participants' direct line of gaze (e.g., Vickers 2007). Furthermore, we used the images of each camera separately to provide measures of visual orientation (scene camera) and blink behavior (eye camera).

\section{Training sessions}

Training sessions were performed at different locations, thereby providing the desired context for each of the exercises. No measures were taken except for a manipulation check of pressure (see dependent variables).

Dependent variables

\section{Manipulation check}

To check whether our pressure manipulation was successful, participants' state anxiety, mean heart rate, and perceived mental effort, were assessed in each condition and each training session by using a visual-analog scale called the "anxiety thermometer" (Houtman and Bakker 1989), a heart rate recorder, and the rating scale mental effort (RSME; Zijlstra 1993), each of which has been used successfully in earlier studies (e.g., Nieuwenhuys and Oudejans 2010; Oudejans and Pijpers 2009) and with satisfying psychometric properties (Houtman and Bakker 1989; Veltman and Gaillard 1996; Zijlstra 1993).

\section{Shot accuracy}

Shot accuracy was assessed by counting the number of hits on each of the designated target areas and computing the mean percentage of hits for each condition (cf. Oudejans 2008).

\section{Movement speed}

Using the shooting times obtained with the shot timer, response and total performance times were determined, operationalized as the time between the start of each trial and the participant's first shot (response time) and last shot (total performance time). Reload times were defined as the time between the participant's second and third shot and were calculated using the recordings of the digital video camera.

\section{Visual orientation}

Using the images of the scene camera, participants' visual orientation was measured in two ways. First, at the exact 
moments of each shot, we assessed how much of the opponent was visible on a scale from 1 (not visible at all; looking down) to 5 (entirely visible; looking straight ahead). Second, during reloading, we calculated the percentage of trials on which the opponent was not visible because participants turned away from the opponent to reload their handgun.

\section{Blink behavior}

Using the images of the eye camera, blink rate was assessed by counting the number of times participants closed their eyes on each trial. Second, the average amount of time that participants had their eyes closed during each trial was calculated, and was expressed as a $\%$ of total performance time.

\section{Gaze behavior}

Based on a random selection of three trials per condition, per test, we analyzed the total duration of fixations to a number of distinguished locations. These locations included (a) target-related locations, defined as the target at which participants were supposed to shoot (b) threatrelated locations, defined as the opponent's gun and face, and (c) other locations, defined as the participants' own gun, the wall or the ground. For analysis, the total duration of fixations to different locations was expressed as a percentage of the total duration of fixations to all locations (total viewing time). Furthermore, we calculated participants' scan ratio, which was defined as the total number of fixations across all locations divided by the total duration of those fixations in seconds (cf. Nieuwenhuys et al. 2008). Finally, we calculated the average duration of the final fixations on the target until the exact moment of shooting (e.g., Wilson et al. 2009). In all cases, the minimum duration of a fixation was set at $100 \mathrm{~ms}$, corresponding to 3 frames of the video data (Vickers 2007).

\section{Procedure}

\section{Test sessions}

At each test, participants performed individually and started with either the LA or HA condition. Standing in front of the opponent (before starting their first trial in any of the conditions), they received instructions about the exercise and were reminded about the specific circumstances under which their performance would occur. In both conditions, participants were instructed to perform the exercise in a relatively quick fashion, but to make sure that they would always shoot as accurately as possible. Directly following the exercise in a specific condition (i.e., after the 10th trial), measurements were ended and participants completed an anxiety thermometer and mental effort scale, indicating how they had felt during their performance in that condition. Then, participants took a 5-min break before starting with the other condition. After finishing both conditions, participants were debriefed in a separate room to share their experiences.

\section{Training sessions}

During the training exercises, participants also performed individually, either against a real opponent (experimental group) or the mannequin/cardboard targets (control group). Heart rate measurements were started before the first exercise of each session. After finishing the last exercise, heart rate measurements were ended and participants completed an anxiety thermometer and mental effort scale.

\section{Statistical analysis}

Following the aim of our study, we chose to separately establish the short- and long-term effects of our training sessions. That is, we first wanted to establish the immediate effects of training with anxiety-and find out which mechanisms are responsible for the observed effectsbefore we examined the extent to which these effects may be maintained over a longer period of time. As such, we first compared the results on pretest and posttest (shortterm effects) and then those on the posttest and retention test (long-term effects). In both cases, our analyses consisted of $2 \times 2 \times 2$ (condition $\times$ test $\times$ group) ANOVAs with repeated measures on condition and test. For the training sessions, differences between groups in anxiety, effort, and heart rate (averaged over the different sessions) were analyzed using between-subject ANOVAs. When needed, post hoc pairwise comparisons were made with Bonferroni correction. For each analysis, effect sizes (Cohen's $f$ ) were calculated. Effect sizes of 0.2 or less, about 0.3 , and 0.4 or more, represented small, moderate, and large differences, respectively (Cohen 1988).

\section{Results}

Manipulation checks

Test sessions

Anxiety scores, mean heart rates, and mental effort scores at each of the three tests are presented in Table 1. 
Table 1 Means $(M)$ and standard deviations $(S D)$ of the anxiety scores, mean heart rates, and mental effort scores of both groups on the pretest, training sessions, posttest, and retention test and under the low-anxiety $(L A)$ and high-anxiety $(H A)$ conditions

\begin{tabular}{|c|c|c|c|c|c|c|c|c|}
\hline \multirow[t]{2}{*}{ Variable } & \multirow[t]{2}{*}{ Group } & \multicolumn{2}{|l|}{ Pretest } & \multirow{2}{*}{$\begin{array}{l}\text { Training } \\
\text { sessions } \\
\text { Training } \\
\text { M (SD) }\end{array}$} & \multicolumn{2}{|l|}{ Posttest } & \multicolumn{2}{|l|}{ Retention test } \\
\hline & & $\begin{array}{l}\text { LA } \\
\text { M (SD) }\end{array}$ & $\begin{array}{l}\mathrm{HA} \\
\mathrm{M}(\mathrm{SD})\end{array}$ & & $\begin{array}{l}\text { LA } \\
\text { M (SD) }\end{array}$ & $\begin{array}{l}\mathrm{HA} \\
\mathrm{M}(\mathrm{SD})\end{array}$ & $\begin{array}{l}\text { LA } \\
\text { M (SD) }\end{array}$ & $\begin{array}{l}\text { HA } \\
\text { M (SD) }\end{array}$ \\
\hline \multirow[t]{2}{*}{ Anxiety $(0-10)$} & Experimental & $1.97(1.46)$ & $4.59(2.37)$ & $4.42(1.73)$ & 1.77 (1.19) & $3.94(2.22)$ & $2.68(1.03)$ & 4.88 (1.66) \\
\hline & Control & $2.21(0.46)$ & $5.07(2.07)$ & $2.23(1.27)$ & 2.17 (1.39) & $4.06(1.85)$ & $1.75(1.38)$ & $4.21(2.18)$ \\
\hline \multirow{2}{*}{$\begin{array}{l}\text { Heart rate (beats/ } \\
\text { min) }\end{array}$} & Experimental & $87.22(14.08)$ & $93.44(15.49)$ & $90.90(11.92)$ & $90.00(18.00)$ & 98.11 (14.79) & $90.50(16.78)$ & 91.75 (18.48) \\
\hline & Control & $98.82(15.70)$ & $104.36(22.77)$ & $91.02(9.83)$ & 91.55 (14.63) & $96.90(14.79)$ & $88.50(11.70)$ & $92.50(13.06)$ \\
\hline \multirow{2}{*}{$\begin{array}{l}\text { Mental effort } \\
(0-150)\end{array}$} & Experimental & 39.89 (15.13) & $66.33(13.73)$ & 59.04 (17.17) & $41.89(20.36)$ & $57.11(18.94)$ & $50.38(18.32)$ & $66.75(14.43)$ \\
\hline & Control & $41.91(12.21)$ & $65.73(18.04)$ & 43.77 (17.69) & 34.55 (17.76) & $54.45(22.27)$ & $30.70(17.20)$ & $52.50(20.65)$ \\
\hline
\end{tabular}

\section{Pretest-posttest comparison}

The ANOVA that was executed to compare anxiety scores on the pretest and posttest showed a significant main effect of condition and a significant interaction between condition and test, $F(1,23)=60.95, P<0.001, f=2.65$ and $F(1$, $23)=6.48, P=0.018, f=0.28$ (all other $P$ s $>0.05$ ). Post hoc comparisons on this interaction effect showed that although anxiety scores were significantly higher in the HA condition on both tests $(P \mathrm{~s}<0.001)$, the HA scores on the posttest were somewhat lower than the HA scores on the pretest $(P=0.014)$. LA scores did not differ significantly between the two tests $(P=0.65$; See Table 3$)$.

The ANOVAs that was executed on the mean heart rates only rendered a significant main effect of condition, $F(1$, 19 ) $=15.75, P=0.001, f=0.83$ (all other $P \mathrm{~s}>0.11$ ), indicating that mean heart rate was consistently higher in the HA condition than in the LA condition. ${ }^{3}$

Finally, the ANOVA that was executed on the mental effort scores rendered significant main effects of condition and test, $F(1,24)=70.76, P<0.001, f=2.95$ and $F(1$, $24)=5.82, P=0.024, f=0.24$ (all other $P$ s $>0.07$ ), indicating that although mental effort scores were consistently higher in the HA condition than in the LA condition, they were somewhat lower on the posttest than on the pretest (Table 3).

\section{Posttest-retention test comparison}

The ANOVAs that were executed to compare anxiety scores, mean heart rates, and mental effort scores on the posttest and the retention test only rendered significant main effects of condition, $F(1,21)=50.15, P<0.001$,

\footnotetext{
${ }^{3}$ Due to incidental malfunctioning of the equipment, heart rate data were not available for all participants. Hence, statistical analyses were performed for 9 (experimental group) and 12 (control group) participants at the pretest-posttest comparison, and 8 (experimental group) and 11 (control group) participants at the posttest-retention test comparison.
}

$f=2.39, \quad F(1,17)=15.93, \quad P=0.001, \quad f=0.94, \quad$ and $F(1,22)=36.82, \quad P<0.001, \quad f=1.67 \quad$ (all other $P$ s $>0.15)$, indicating that irrespective of test and group, anxiety scores, mean heart rate, and mental effort scores were significantly higher in the HA condition than in the LA condition (see Table 1).

Taken together, these results imply that our pressure manipulation was successful throughout the experiment and for both groups.

\section{Training sessions}

Anxiety scores, mean heart rates, and mental effort scores, averaged over the different training sessions, are also presented in Table 1. The ANOVAs that were executed on these variables showed that anxiety as well as effort scores were significantly higher for the experimental group than for the control group, $F(1,26)=14.171, P=0.001$, $f=0.75$ and $F(1,26)=5.167, P=0.032, f=0.45$ (see Table 1). There was no significant difference in heart rate between groups $(P=0.98)$. Nevertheless, these results imply that the experimental group experienced more anxiety during the training sessions than the control group.

\section{Shot accuracy}

Mean shot accuracy during the tests is presented in Table 2.

\section{Pretest-posttest comparison}

The ANOVA comparing shot accuracy on the pretest and posttest showed a significant main effect of condition, $F(1,25)=41.16, P<0.001, f=1.28$, which was overruled by a significant three-way interaction between group, test, and condition, $F(1,25)=4.24, P=0.05, f=0.41$. Pairwise comparisons on this three-way interaction showed that at the pretest, the shot accuracy of both groups was lower in the HA than in the LA condition (in both cases 
Table 2 Means $(M)$ and standard deviations $(S D)$ of shot accuracy for both groups on the pretest, posttest and retention test and under the lowanxiety $(L A)$ and high-anxiety $(H A)$ conditions

\begin{tabular}{|c|c|c|c|c|c|c|c|}
\hline \multirow[t]{3}{*}{ Variable } & \multirow[t]{3}{*}{ Group } & \multicolumn{2}{|l|}{ Pretest } & \multicolumn{2}{|l|}{ Posttest } & \multicolumn{2}{|l|}{ Retention test } \\
\hline & & LA & HA & LA & HA & LA & HA \\
\hline & & M (SD) & $\mathrm{M}(\mathrm{SD})$ & $\mathrm{M}(\mathrm{SD})$ & M (SD) & M (SD) & M (SD) \\
\hline \multirow[t]{2}{*}{ Shot accuracy (\%) } & Experimental & $93.54(5.88)$ & 79.15 (14.07) & $90.92(9.10)$ & $85.15(10.43)$ & 89.67 (7.96) & $86.42(7.67)$ \\
\hline & Control & $89.14(7.81)$ & 74.64 (18.94) & $88.21(8.41)$ & $71.00(18.47)$ & 91.54 (6.69) & $87.85(6.67)$ \\
\hline
\end{tabular}

Percentages $(\%)$ refer to the mean percentage of target hits in each condition

$P=0.001$; see Table 2). At the posttest, however (i.e., after the training sessions), this difference between conditions was eliminated by the experimental group $(P=0.061)$, while the performance of the control group was still equally affected by anxiety $(P<0.001$; see Table 2). In line with this result, at the posttest, the HA performance of the experimental group was significantly better than the HA performance of the control group $(P=0.023)$.

\section{Posttest-retention test comparison}

The ANOVA comparing shot accuracy on the posttest and retention test showed significant main effects of test, $F(1,23)=4.99, P=0.036, f=0.47$, and condition, $F(1$, $23)=21.44, P<0.001, f=0.93$, and a significant interaction between test and condition, $F(1,23)=9.52$, $P=0.005, f=0.64$. Finally, the three-way interaction between group, test, and condition just failed to reach significance, $F(1,23)=3.95, P=0.059, f=0.41$. Follow-up analyses on this interaction confirmed the observed posttest group differences, indicating a decrease in shot accuracy under anxiety for the control group $(P<0.001)$, but not for the experimental group $(P>0.05)$. Furthermore, they showed that, at the retention test, shot accuracy of the experimental group did not deteriorate as a result of anxiety $(P=0.23$; see Table 2$)$. Unexpectedly, however, this was also the case for the control group $(P=0.16)$, who performed significantly better in the HA condition at the retention test than at the posttest $(P<0.001$; see Table 2$)$.

Movement speed, visual orientation, and blink behavior

With respect to the results on movement speed, visual orientation, and blink behavior (see Table 3), statistical analyses occasionally rendered significant effects, but in most cases these were unrelated to group and shot accuracy. Therefore, and due to limited article space, only the most important results will be mentioned. ${ }^{4}$ Significant main

\footnotetext{
${ }^{4}$ A more detailed description of the statistical analyses for movement speed, visual orientation, and blink behavior can be obtained from the authors upon request.
}

effects of test showed that, overall, participants became faster in handling their handgun after training. Movement times decreased from pretest to posttest, with $F(1,25)=$ 5.22, $P=0.031, f=0.21 ; F(1,25)=67.63, P<0.001$, $f=2.70$; and $F(1,25)=43.06, P<0.001, f=1.73$, for response time, reload time, and total performance time, respectively, and remained constant from posttest to retention test $(P \mathrm{~s}>0.25$; see Table 3$)$. In addition, a significant main effect of condition (pretest-posttest comparison) showed that participants' reaction times were generally faster in the HA than in the LA conditions, $F(1,25)=8.03, P=0.009, f=0.32$ (Table 3 ).

With respect to visual orientation and blink behavior, (marginally) significant main effects of condition (pretestposttest comparison) indicated that participants turned away more often during reloading, $F(1,20)=15.46$, $P=0.001, f=0.77$, blinked more often, $F(1,14)=5.96$, $P=0.027, f=0.43$, and closed their eyes for a larger part of the trials, $F(1,14)=4.51, P=0.052, f=0.32$, in the HA than in the LA conditions. For visual orientation, during shooting, no significant main effects were found $(P \mathrm{~S}>0.15){ }^{5}$

\section{Gaze behavior}

As was also the case in Nieuwenhuys and Oudejans (2010), full gaze data were available for only a small selection of participants due to large changes in visual orientation (4\%), complete or partial closing of the eyes $(22 \%)$, and other strongly affected behavior (24\%) under anxiety. For the pretest, this meant that gaze data (available for only three participants) could not be statistically analyzed. For the posttest and the retention test, however, data were available for eight participants (four experimental, four control) and ten participants (five experimental, five control), respectively. Because data were available for different participants at each test, gaze data were analyzed separately for each group (experimental and control), using $2 \times 2$

\footnotetext{
5 Because some participants reacted to our pressure manipulation by completely closing their right eye, blink behavior data were only available for 16 participants (10 experimental, 6 control; see also Gaze Behavior).
} 
Table 3 Means $(M)$ and standard deviations $(S D)$ of the of the results on movement times, visual orientation, and blink behavior of both groups on the pretest posttest and retention test and under the low-anxiety $(L A)$ and high-anxiety $(H A)$ conditions

\begin{tabular}{|c|c|c|c|c|c|c|c|}
\hline \multirow[t]{2}{*}{ Variable } & \multirow[t]{2}{*}{ Group } & \multicolumn{2}{|l|}{ Pretest } & \multicolumn{2}{|l|}{ Posttest } & \multicolumn{2}{|l|}{ Retention test } \\
\hline & & $\begin{array}{l}\text { LA } \\
\text { M (SD) }\end{array}$ & $\begin{array}{l}\mathrm{HA} \\
\mathrm{M}(\mathrm{SD})\end{array}$ & $\begin{array}{l}\text { LA } \\
\text { M (SD) }\end{array}$ & $\begin{array}{l}\mathrm{HA} \\
\mathrm{M}(\mathrm{SD})\end{array}$ & $\begin{array}{l}\text { LA } \\
\text { M (SD) }\end{array}$ & $\begin{array}{l}\mathrm{HA} \\
\mathrm{M}(\mathrm{SD})\end{array}$ \\
\hline \multicolumn{8}{|l|}{ Movement times } \\
\hline \multirow[t]{2}{*}{ Reaction time (s) } & Experimental & $2.09(0.42)$ & $1.91(0.37)$ & $1.97(0.30)$ & $1.90(0.34)$ & $1.89(0.43)$ & $1.90(0.48)$ \\
\hline & Control & $2.31(1.16)$ & $2.12(0.99)$ & $1.90(0.47)$ & $1.88(0.76)$ & $2.09(0.98)$ & $1.95(0.92)$ \\
\hline \multirow[t]{2}{*}{ Reload time (s) } & Experimental & $6.19(0.84)$ & $6.16(1.13)$ & $5.56(0.85)$ & $5.42(0.81)$ & $5.14(0.67)$ & $5.18(0.83)$ \\
\hline & Control & $6.62(1.39)$ & $6.62(0.94)$ & $5.63(0.68)$ & $5.71(1.02)$ & $5.84(1.08)$ & $5.78(1.05)$ \\
\hline \multirow[t]{2}{*}{ Total performance time (s) } & Experimental & $11.74(1.45)$ & $11.61(1.82)$ & $10.72(1.09)$ & $10.39(1.15)$ & $10.09(1.35)$ & $10.23(1.47)$ \\
\hline & Control & $12.72(2.89)$ & $12.40(2.45)$ & $10.85(1.35)$ & $11.09(2.34)$ & $11.49(2.68)$ & $11.10(2.76)$ \\
\hline \multicolumn{8}{|l|}{ Visual orientation } \\
\hline \multirow[t]{2}{*}{ During shooting (1-5) } & Experimental & $4.63(0.45)$ & $4.41(0.80)$ & $4.29(0.82)$ & $4.36(0.84)$ & $4.43(0.59)$ & $4.25(0.56)$ \\
\hline & Control & $4.56(0.63)$ & $4.57(0.68)$ & $4.83(0.29)$ & $4.15(1.28)$ & $4.58(0.45)$ & $4.49(0.64)$ \\
\hline \multirow[t]{2}{*}{ During reloading $(\%)$} & Experimental & $25.65(33.70)$ & $56.46(47.39)$ & $39.80(44.53)$ & $54.91(44.44)$ & $38.96(41.74)$ & $62.05(46.07)$ \\
\hline & Control & $9.00(25.14)$ & $34.00(35.88)$ & $8.00(22.01)$ & $43.56(35.89)$ & $21.54(37.38)$ & $19.17(29.57)$ \\
\hline \multicolumn{8}{|l|}{ Blink behavior } \\
\hline \multirow[t]{2}{*}{ Blink rate (blinks/trial) } & Experimental & $2.95(1.71)$ & $4.41(2.53)$ & $2.49(1.30)$ & $3.53(1.96)$ & $1.84(1.44)$ & $4.80(2.38)$ \\
\hline & Control & $2.84(2.65)$ & $2.48(1.82)$ & $1.94(1.10)$ & $2.32(1.53)$ & $2.76(2.36)$ & $4.64(4.49)$ \\
\hline \multirow[t]{2}{*}{ Eyes closed (\%) } & Experimental & $5.80(3.59)$ & $7.98(4.08)$ & $4.28(2.26)$ & $5.93(3.26)$ & $2.41(1.43)$ & $6.44(3.82)$ \\
\hline & Control & $4.78(3.28)$ & $4.20(2.50)$ & $3.69(2.14)$ & $3.79(2.41)$ & $2.72(1.85)$ & $5.24(4.20)$ \\
\hline
\end{tabular}

Percentages (\%) for visual orientation refer to the percentage of trials in which participants turned away from the opponent during reloading. Percentages $(\%)$ for blink behavior refer to the percentage of total performance time during which participants had their eyes closed

(test $\times$ condition) mixed design ANOVAs, with repeated measures on condition, and with test now as a betweensubject factor. As such, no explicit comparisons were made between the results of the experimental and control groups, but the analyses still provide an interesting description of the gaze behavior that was characteristic for participants of each group, respectively. An overview of the results on gaze behavior is presented in Table 4. For each variable, results are presented first for the participants of the experimental group (posttest and retention test sample) and then for the participants of the control group (posttest and retention test sample).

\section{Scan ratio}

As can be seen in Table 4 (top row), the scan ratios for the experimental group samples were relatively low (around or below 0.6). In line with the results for shot accuracy, which was maintained under pressure on the posttest, no significant changes were observed between tests and conditions (all $P$ s $>0.51$ ).

For the control group, scan ratios were higher for the posttest sample, especially in the HA condition (Table 4, second row). Although in both samples scan ratios increased under anxiety, $F(1,7)=10.85, P=0.013, f=1.25$, a significant main effect of test showed that (in line with the improvements on shot accuracy) the sample at the retention test was more calm in their gaze behavior, as was indicated by significantly lower scan ratios, $F(1,7)=10.68$, $P=0.014, f=1.24$.

\section{Total duration of fixations}

For the experimental group samples, the total duration of fixations on the targets somewhat decreased as a result of anxiety, as was indicated by a significant main effect of condition, $F(1,7)=9.90, P=0.016, f=1.19$. Nevertheless, visual inspection of the data (see Table 4) showed that despite this consistent decrease, in all cases, the percentages of viewing time remained relatively high (i.e., above $80 \%$ ). The total duration of fixations on threatrelated locations showed a general increase under anxiety, $F(1,7)=8.46, P=0.023, f=1.10$. No significant differences were found for the duration of fixations on other locations $(P \mathrm{~s}>0.12)$.

For the control group samples, the total duration of fixations on the targets decreased significantly under anxiety, $F(1,7)=8.22, P=0.024, f=1.08$. In line with their HA shot accuracy, which was low on the posttest but better on the retention test, the duration of target-related fixations was well below $80 \%$ for the posttest sample, but above $90 \%$ for the retention test sample (Table 4). At the same 
Table 4 Means $(M)$ and standard deviations $(S D)$ of the results on gaze behavior of both groups on the posttest and retention test and under the low-anxiety $(L A)$ and high-anxiety $(H A)$ conditions

\begin{tabular}{|c|c|c|c|c|c|}
\hline \multirow[t]{2}{*}{ Variable } & \multirow[t]{2}{*}{ Group } & \multicolumn{2}{|l|}{ Posttest } & \multicolumn{2}{|l|}{ Retention test } \\
\hline & & $\begin{array}{l}\text { LA } \\
\text { M (SD) }\end{array}$ & $\begin{array}{l}\mathrm{HA} \\
\mathrm{M}(\mathrm{SD})\end{array}$ & $\begin{array}{l}\text { LA } \\
\text { M (SD) }\end{array}$ & $\begin{array}{l}\mathrm{HA} \\
\mathrm{M}(\mathrm{SD})\end{array}$ \\
\hline \multirow[t]{2}{*}{ Scan ratio (fixations/second) } & Experimental & $0.60(0.14)$ & $0.64(0.15)$ & $0.54(0.22)$ & $0.54(0.19)$ \\
\hline & Control & $0.76(0.23)$ & $0.87(0.23)$ & $0.41(0.05)$ & $0.51(0.13)$ \\
\hline \multicolumn{6}{|l|}{ Total duration of fixations (\%) } \\
\hline \multirow[t]{2}{*}{ Target-related } & Experimental & $91.84(7.54)$ & $82.03(13.74)$ & $94.56(4.98)$ & $88.72(9.02)$ \\
\hline & Control & $92.59(8.33)$ & $75.74(17.78)$ & $97.30(3.46)$ & $91.21(9.61)$ \\
\hline \multirow[t]{2}{*}{ Threat-related } & Experimental & $0.48(0.95)$ & $4.62(6.33)$ & $0.00(0.00)$ & $6.95(5.13)$ \\
\hline & Control & $2.68(3.67)$ & $9.78(15.43)$ & $1.15(2.58)$ & $4.44(6.32)$ \\
\hline \multirow[t]{2}{*}{ Other } & Experimental & $7.69(7.30)$ & $13.36(9.41)$ & $5.44(4.98)$ & $4.33(4.55)$ \\
\hline & Control & $4.73(4.67)$ & $14.49(7.62)$ & $1.55(3.13)$ & $4.35(3.91)$ \\
\hline \multirow[t]{2}{*}{ Final fixation on the targets (s) } & Experimental & $1.76(0.25)$ & $1.84(0.38)$ & $2.11(0.84)$ & $2.00(0.68)$ \\
\hline & Control & $1.46(0.25)$ & $1.31(0.39)$ & $2.01(0.27)$ & $1.89(0.47)$ \\
\hline
\end{tabular}

Percentages (\%) refer to the total duration of fixations to different locations relative to the duration of fixations to all locations

time, the total duration of threat-related fixations showed a small but nonsignificant increase under anxiety $(P=0.19$; see Table 4). For the total duration of fixations on other locations, a significant interaction between test and condition was found, $F(1,7)=6.86, P=0.034, f=0.99$. Pairwise comparisons showed that the duration of fixations to other locations was significantly higher under anxiety for the posttest sample $(P=0.002)$ but not for the retention test sample, thereby explaining the decreased duration of target-related fixations that was observed at the HA posttest.

\section{Final fixations on the target}

As can be seen in Table 4, both experimental group samples executed relatively long final fixations on the targets, showing no differences between tests and conditions (all $P$ s $>0.49)$.

For the control group samples, a significant main effect of test showed that final fixations on the target were significantly shorter for the posttest sample (when shot accuracy was poor) than for the retention test sample (when shot accuracy was better), $F(1,7)=9.00, P=0.020$, $f=1.13$.

\section{Discussion}

We investigated the short- and long-term effects of training with anxiety on police officers' shooting behavior under pressure. Using a pretest, posttest, and retention test design, 27 police officers executed a shooting exercise against opponents who did (high-anxiety condition) or did not (low-anxiety condition) shoot back using colored soap cartridges. During a series of four training sessions, which were executed between pre- and posttest, the experimental group practiced with anxiety, while the control group practiced without anxiety. At the pretest, the shot accuracy of both groups showed a strong and significant decrease under anxiety, with hit percentages dropping from about $90 \%$ or more in the low-anxiety condition to $80 \%$ or less in the high-anxiety condition (Table 2; cf. Oudejans 2008; Nieuwenhuys and Oudejans 2010). At the posttest, the control group still performed equally worse under anxiety, while the experimental group showed considerable improvement. These results are in line with the findings from Oudejans (2008) and Oudejans and Pijpers (2009, 2010) and indicate that training with anxiety can help to improve performance under pressure.

In addition, the results provide an indication that positive effects of training with anxiety may be maintained over a longer period of time. That is, the positive effects of training with anxiety that were observed for the experimental group at the posttest, were still visible at the retention test, where they shot equally well with and without anxiety (see Table 2). Nevertheless, some caution is warranted in interpreting these results because the overarching three-way interaction that was present at the pretest-posttest comparison just failed to reach significance at the posttest-retention test comparison $(P=0.059$; see Results). As such, more research is needed to substantiate our findings.

Unexpectedly, at the retention test, the control group also seemed to maintain their level of performance under anxiety. Note, however, that although the experimental group had taken 48 additional shots under high anxiety before starting the retention test (i.e., 80 shots during the pre- and posttest +48 during training), the 80 shots that 
were taken under high anxiety by the control group (i.e., during the pre- and posttest) may already have been sufficient for them to create a learning effect. On the other hand, it could also be that the control group "caught up" because at the time of the retention test all participants (experimental and control group) had gained considerable experience by just shooting at the targets. However, because the participants already were experienced shooters at the outset of the experiment, it is more likely that specific experience with performing under anxiety was responsible for the observed effects. This argument is confirmed by the fact that performance under low anxiety showed no improvement over time.

In line with attentional control theory (Eysenck et al. 2007), participants of both groups consistently reported more mental effort in the high-anxiety than in the lowanxiety conditions (see Table 1), indicating that they actively tried to compensate for the negative effects of anxiety on their performance. At first, their efforts were ineffective, as the shot accuracy of both groups decreased under anxiety. However, as participants gained more experience with performing under high levels of anxiety, it seemed that extra mental effort became more effective. In line with previous studies, the results suggest that through repeated experience, individuals may learn to more effectively recalibrate their actions to the changed circumstances accompanying pressure and anxiety (Oudejans and Nieuwenhuys 2009). This is also what participants reported in the debrief interviews that were carried out at the end of each test session. At the pretest, participants reported speeding up their performance under anxiety, hereby failing to concentrate on their aiming and accuracy. Later, at the posttest (experimental group) and retention test (experimental group and control group), they reported that more experience with performing under anxiety enabled them to focus more strongly on their shot accuracy under these circumstances.

Based on attentional control theory (Eysenck et al. 2007), we hypothesized that with respect to our measures of shooting behavior (e.g., movement times, visual orientation, blink behavior), initial reductions in efficiency may be eliminated after training with anxiety. In line with the results of Nieuwenhuys and Oudejans (2010), our participants showed faster response times under anxiety, turned away more often, and executed more blinks, which indicates an increase in stimulus-driven behavior and a reduction in efficiency that could potentially have influenced their shot accuracy (Eysenck et al. 2007). However, other than in Nieuwenhuys and Oudejans, the changes were small, and could not explain the observed pattern of results for shot accuracy. One possible explanation for this is that the participants were more experienced $(M=11.56$ years of working experience, $\mathrm{SD}=6.28$ ) than those of Nieuwenhuys and Oudejans $(M=3.4$ years of working experience, $t(26)=6.75, P<0.001$; one-sample $t$-test , which perhaps made their performance more robust under pressure. This is confirmed by the fact that the initial reduction in shot accuracy that we found ( $M=14.96, \mathrm{SD}=13.35)$ was substantially smaller than the reduction in shot accuracy that was found by Nieuwenhuys and Oudejans, $M=22.73$, $t(26)=3.02, P=0.006$ (one-sample $t$-test).

Although the changes in movement speed, visual orientation, and blink behavior could not explain the observed pattern of results for shot accuracy, it appeared that changes in gaze behavior could. In general, the analyses of participants' gaze behavior showed that good performance under anxiety was related to maintaining a relatively calm gaze behavior. When participants performed well with (or without) anxiety, this was accompanied by relatively low scan ratios. These results confirm earlier findings by Murray and Janelle (2003) and indicate that while anxiety may initially cause individuals to be more hypervigilant in their gaze behavior, training with anxiety might help to regain the calmness and attentional control that is necessary to achieve optimal performance (Eysenck et al. 2007; Oudejans and Nieuwenhuys 2009).

In line with attentional control theory (Eysenck et al. 2007), participants consistently spent more time fixating threatrelated sources of information when they were anxious. However, since this did not change as participants gained more experience with performing under anxiety (i.e., improved their shot accuracy), it must be assumed that looking at threat-related sources of information does not necessarily have a negative influence on task performance. Instead, it appeared to be an increase in the duration of fixations to other locations that caused the observed drop in target-related visual attention (see Table 4, posttest, control group). Although attentional control theory predicts that under anxiety goaldirected attention decreases as a result of increased attention to threat-related information, our results suggest that at least visually, this does not always have to be the case. In the current study, it appeared that despite increased attention to threatrelated information, shot accuracy was good as long as participants spent enough time fixating on the targets and minimized distraction by other sources of information (cf. Behan and Wilson 2008; Wilson et al. 2009). ${ }^{6}$

\footnotetext{
${ }^{6}$ Although in other circumstances (e.g., during actual police work) paying attention to threat-related information such as the head and gun of the opponent is essential, and can be considered task-relevant, this was not the case in the current experimental task. The opponent in the HA condition did not move, had his gun aimed at the participant throughout the trial, and shot back regardless of the participant's performance (see Experimental Task and Conditions). Furthermore, because the participants' were not allowed to run away or seek cover (i.e., they had to strictly follow the experimental protocol and hit the targets as often as possible) only fixations on the targets were considered task-relevant.
} 
This line of thought is supported by the analyses of the final fixations on the targets, just before shooting. In line with the results of Wilson et al. (2009), the current study showed that relatively long final fixations on the targets were indeed associated with good performance. Again, when participants performed well under anxiety, this was accompanied by relatively long final fixations on the targets (cf. Behan and Wilson 2008; Vickers and Williams 2007), which potentially indicates regained control of goal-directed attention after training (Eysenck et al. 2007; Oudejans and Nieuwenhuys 2009). When performance was bad (control group, highanxiety posttest) this was accompanied by relatively short final fixations on the targets, indicating that goal-directed attentional control may have been reduced (Eysenck et al. 2007; Oudejans and Nieuwenhuys 2009).

Of course, our results on gaze behavior should be treated with caution. Gaze data were available for only a limited number of participants. Furthermore, as the participants on the posttest were not the same as those on the retention test, it was impossible to conduct a true within-subject analysis with repeated measures on test. Nevertheless, we were the first to investigate the effects of (training with) anxiety on perceptual-motor performance and gaze behavior within a pretest, posttest, and retention test design. This made it possible to test the impact of anxiety on individuals who did and who did not manage to maintain performance under pressure, providing more insight into how individuals may effectively or ineffectively deal with stressors.

In sum, the current study confirms earlier research, in the sense that training with anxiety improves performance under stressful circumstances (Oudejans 2008; Oudejans and Pijpers 2009, 2010). In addition, we provided indications that these positive effects of training with anxiety may be robust over a relatively long period of time (i.e., 4 months). As such, training with anxiety may proof a fruitful and realistic endeavor for professional police practice and education. Finally, and in line with our predictions based on attentional control theory (Eysenck et al. 2007) and ideas of Oudejans and Nieuwenhuys (2009), the results on mental effort and gaze behavior suggest that positive effects of training with anxiety may be explained by improved self-regulatory processes which cause individuals to become more effective in paying attention to task-relevant sources of information.

Acknowledgments This study was funded by The Police Research Program of the Netherlands (www.politieenwetenschap.nl). The authors would like to thank Gerard Willemsen and the police firearms instructors of the Police Trainingcenter in Almere, The Netherlands, for their help in conducting the experiment.

Open Access This article is distributed under the terms of the Creative Commons Attribution Noncommercial License which permits any noncommercial use, distribution, and reproduction in any medium, provided the original author(s) and source are credited.

\section{References}

Anderson S, Litzenberger R, Plecas DB (2002) Physical evidence of police officer stress. Polic Int J Polic Strateg Manag 25:399-420

Behan M, Wilson M (2008) State anxiety and visual attention: the role of the quiet eye period in aiming to a far target. J Sport Sci 26:207-215

Beilock SL, Carr TH (2001) On the fragility of skilled performance: what governs choking under pressure? J Exp Psychol Gen 130:701-725

Cohen J (1988) Statistical power analysis for the behavioural sciences, 2nd edn. Lawrence Erlbaum, Hillsdale

Coombes SA, Higgins T, Gamble KM, Cauraugh JH, Janelle CM (2009) Attentional control theory: anxiety, emotion, and motor planning. J Anxiety Disord 23:1072-1079

Deffenbacher KA, Bornstein BH, Penrod SD, McGorty EK (2004) A meta-analytic review of the effects of high stress on eyewitness memory. Law Hum Behav 28:687-706

Driskell JE, Johnston JH, Salas E (2001) Does stress training generalize to novel settings? Hum Factors 43:99-110

Eysenck MW, Derakshan N, Santos R, Calvo MG (2007) Anxiety and cognitive performance: attentional control theory. Emotion 7:336-353

Houtman ILD, Bakker FC (1989) The anxiety thermometer: a validation study. J Pers Assess 53:575-582

Morrison GB, Vila BJ (1998) Police handgun qualification: practical measures or aimless activity? Polic Int J Polic Strateg Manag 21:510-533

Murray KR (2004) Training at the speed of life, vol 1: the definitive textbook for police and military reality based training. Armiger Publications, Gotha

Murray NP, Janelle CM (2003) Anxiety and performance: a visual search examination of the processing efficiency theory. J Sport Exerc Psychol 25:171-187

Naeyé J, Timmer JS, Beijers G (2001) Politiële geweldrapportage 1998-2000. [Police Violence Reports 1998-2000]. Centrum voor Politiewetenschappen, Amsterdam

Nieuwenhuys A, Oudejans RRD (2010) Effects of anxiety on handgun shooting behavior of police officers: a pilot study. Anxiety Stress Coping 23:225-233

Nieuwenhuys A, Pijpers JR, Oudejans RRD, Bakker FC (2008) The influence of anxiety on visual attention in climbing. J Sport Exerc Psychol 30:171-185

Nieuwenhuys A, Caljouw SR, Leijsen MR, Schmeits BAJ, Oudejans RRD (2009) Quantifying police officers' arrest and self-defence skills: does performance decrease under pressure? Ergonomics 52:1460-1468

Oudejans RRD (2008) Reality based practice under pressure improves handgun shooting performance of police officers. Ergonomics 51:261-273

Oudejans RRD, Nieuwenhuys A (2009) Perceiving and moving in sports and other high-pressure contexts. In: Raab M, Johnson JG, Heekeren HR (eds) Mind and motion: the bidirectional link between thought and action-Progress in Brain Research, vol 174. Elsevier, Amsterdam, pp 35-48

Oudejans RRD, Pijpers JR (2009) Training with anxiety has a positive effect on expert perceptual-motor performance under pressure. Q J Exp Psychol 62:1631-1647

Oudejans RRD, Pijpers JR (2010) Training with mild anxiety may prevent choking under higher levels of anxiety. Psychol Sport Exerc 11:44-50

Romano JC, Howard JH Jr, Howard DV (2010) One-year retention of general and sequence-specific skills in a probabilistic, serial reaction time task. Memory 18:427-441 
Sauer J, Hockey GRJ, Wastell DG (2000) Effects of training on shortand long-term skill retention in a complex multiple-task environment. Ergonomics 43:2043-2064

Van der Ploeg HM, Defares PB, Spielberger CD (1980) Manual for the Dutch version of the State-Trait Anxiety Inventory. Swets \& Zeitlinger, Lisse

Veltman JA, Gaillard AWK (1996) Physiological indices of workload in a simulated flight task. Biol Psychol 42:323-342

Vickers JN (2007) Perception, cognition and decision training: the quiet eye in action. Human Kinetics, Champaign
Vickers JN, Williams AM (2007) Performing under pressure: the effects of physiological arousal, cognitive anxiety, and gaze control in biathlon. J Mot Behav 39:381-394

Wilson MR, Vine SJ, Wood G (2009) The influence of anxiety on visual attentional control in basketball free throw shooting. J Sport Exerc Psychol 31:152-168

Zijlstra FRH (1993) Efficiency in work behaviour: a design approach for modern tools. Delft University Press, Delft 